\title{
A FORMAÇÃO DE PROFESSORES - EPISTEMOLOGIA E PRÁXIS CRIADORA
}

\author{
TEACHER TRAINING - EPISTEMOLOGY AND CREATIVE PRAXIS
}

\author{
Maria Célia Borges \\ Doutora em Educação/Currículo - PUCSP \\ Pós-doutora em Educação - Feusp. \\ Professora da Universidade Federal de Uberlândia (Faced/UFU) - MG \\ mariacelia@ufu.br \\ Leonice Matilde Richter \\ Doutora em Educação \\ pela Universidade Federal de Uberlândia - UFU \\ Professora da Universidade Federal de Uberlândia (Faced/UFU) - MG \\ leonice@ufu.br
}

\begin{abstract}
Resumo: A formação de professores é uma área de pesquisa que necessita de uma corrente filosófica orientadora. O objetivo do texto é discutir a formação de professores como epistemologia da práxis criadora, cujas reflexões e diálogo são orientados pelo materialismo histórico dialético. A metodologia utilizada foi a pesquisa bibliográfica recorrendo a alguns autores da matriz filosófica como Marx (1982), Vázquez (1977), Vygotsky $(2003,2005)$ e Kosik $(2010)$, bem como ao tema formação de professores com base em autores como Schön (1997), Tardif (2002) e Pimenta (2005), entre outros. Os resultados evidenciaram que nossa compreensão segue na contramão dos racionalistas práticos que concebem a Formação de Professores limitada ao mundo da consciência comum, sem garantir o desenvolvimento do pensamento científico sobre a docência, o qual a subsidia à apropriação e objetivação de uma práxis criadora. Teoria e prática são fundamentais na formação docente, sendo a primeira orientada por uma matriz epistêmica.
\end{abstract}

Palavras-chave: formação de professores; epistemologia; materialismo histórico dialético. teoria e prática; práxis criadora.

\begin{abstract}
Research on teacher training demands a current philosophical guiding. We aim to discuss the training of teachers having as epistemology the creative praxis, with reflections and dialogue guided by historical-dialectical materialism. The methodology used was the bibliographical research based on some authors from the philosophical matrix, such as Marx (1982), Vázquez (1977), Vygotsky $(2003,2005)$ and Kosik (2010) and, on the theme teacher training, Schön (1997) ), Tardif (2002), Pimenta (2005), among others. The results showed that our understanding goes the opposite direction of what practical rationalists announce as they conceive Teacher Training limited to the world of common consciousness, without the guarantee of the development of scientific thinking about teaching, which subsidizes it towards the appropriation and objectification of a creative praxis. Theory and practice are fundamental in teacher training once the first one is guided by an epistemic matrix.
\end{abstract}

Keywords: teacher training; epistemology; historical-dialectical materialism; theory and practice; criative praxis.

Para citar - (ABNT NBR 6023:2018)

BORGES, Maria Célia; RICHTER, Leonice Matilde. A formação de professores - epistemologia e práxis criadora. Eccos - Revista Científica, São Paulo, n. 59, p. 1-16, e13935, out./dez. 2021. Disponível em: https://doi.org/10.5585/eccos.n59.13935. 


\section{Introdução}

A Formação de Professores tornou-se uma área de estudos nas últimas décadas do século XX. No Brasil destacamos como pesquisadores da área Gatti (2001, 2008, 2009, 2011), André (2000, 2009,2010), Freitas (2009), Romanowski (2012), Barreto (2015), Brzezinski (2015), Dourado (2015), entre outros. Esse campo de estudo dialoga bastante com outras áreas, dentre as quais podemos citar a Didática, a Metodologia de Ensino e Prática de Ensino, o Currículo e a Qualidade de Ensino.

Por se tratar de uma área de conhecimento relativamente jovem, a Formação de Professores ainda carece de um aprofundamento teórico como um maior diálogo com a história e a filosofia da educação. Nessa perspectiva, nossa defesa é de que o apoio de uma matriz epistêmica coerente, servindo de alicerce para as metodologias de pesquisa, é o que daria ao campo teórico uma nova e promissora consistência e credibilidade.

A escolha da matriz epistêmica que orienta nossas discussões está fundamentada nos teóricos filiados ao materialismo histórico dialético e correntes próximas, estabelecendo um diálogo especialmente com Marx (1982), Vázquez (1977), Vygotsky (2003,2005), Leontiev (1987), Kosik (2010) e Frigotto (1999).

$\mathrm{Na}$ vertente filosófica que norteia nossas reflexões, já na Grécia antiga, a palavra 'dialética' explicitava uma maneira específica de argumentar para descobrir as contradições contidas no raciocínio - análise, negando, desse modo, a validade da sua argumentação e superando-se por outra - síntese. Assim, para que compreendamos um fenômeno admitindo que ele não está sozinho, percebemos as relações, conexões e, obviamente, que ele influencia e é influenciado. Ademais, o contexto deve ser considerado - a forma de organização da sociedade - pois este também influencia nas determinações políticas, sociais e econômicas. Só a partir de uma visão crítica aguçada é possível perceber os nexos existentes, as considerações polêmicas e as questões ideológicas muitas vezes disfarçadas em discursos de interesses diversos. (DALBERIO \& DALBERIO, 2007)

Entendemos que as pesquisas em torno da temática Formação de Professores têm assumido destaque no debate educacional brasileiro e dentre as produções uma forte corrente epistemológica racionalista-prática tem se sobressaído, sustentada por uma concepção práticoreflexiva de formação docente. Admitimos a tese de que essa corrente teórica de formação foi assumida, dentre outros fatores, nas orientações políticas da educação no país por atender a interesses políticos e ideológicos que contribuem para a perpetuação da estrutura social vigente marcada pela lógica da individualização, do imediatismo, da meritocracia, da centralidade do 
micro, da negação do debate político-ideológico e da negligência quanto à relação escolasociedade. Sem tocar nos fatores sociais excludentes que envolvem o interesse do capital e interferem na educação, as soluções dos problemas educacionais são atribuídas, sobretudo, à prática cotidiana nas escolas.

Essa corrente tem reforçado o discurso da formação prática e não raro enfatiza que os problemas da qualidade da educação são causados pelo despreparo dos professores, pois falta a eles o "saber fazer". Atribuem tal carência, geralmente, aos cursos de licenciatura que se dedicariam mais à formação teórica do que prática. Nesse entremeio, especialmente a partir da implementação das avaliações em larga escala, a partir da década de 1990, a responsabilização docente é apontada como principal fator para os resultados educacionais (RICHTER, 2015). Os dados das avaliações têm apoiado argumentos de que a situação da formação dos professores não tem atendido à demanda da prática docente ${ }^{1}$.

No texto analisamos, inicialmente, as marcas e características da concepção racionalista como campo teórico de formação que tem dado substrato à política de responsabilização dos docentes pelas mazelas da educação. No segundo momento, nos dedicamos à reflexão da Formação de Professores na perspectiva marxista. Corroboramos com o materialismo históricodialético como epistemologia central para a discussão acerca da formação e, nessa perspectiva, trabalhamos no artigo categorias como a constituição do sujeito, a humanização, a dialética, a totalidade, a formação de conceitos científicos que se constituem do abstrato ao concreto, a formação do pensamento teórico, a genericidade para-si (genericidade em-si) e a instrumentalização e objetivação na prática social.

Utilizamos a pesquisa bibliográfica para a construção do referencial teórico baseado em autores que dialogam com a área de estudo e a vertente filosófica escolhida. Esperamos que os resultados deste estudo possam adensar a discussão teórica fundamentada pela filosofia crítica nas investigações sobre Formação de Professores.

\section{Fundamentos e princípios da formação de professores}

Estudiosos como Tardif (2002), Shön (1997; 2000), dentre outros autores, têm reforçado a relevância das experiências práticas vividas pelo docente em seu processo formativo, as quais devem ser amplamente refletidas e constituir-se em base para a busca de alternativas aos problemas que emergem do cotidiano escolar. O conhecimento produzido na e pela prática

\footnotetext{
${ }^{1}$ No Planejamento Político-Estratégico (BRASIL, 1995-1998) o governo FHC assume a tese de que o enfrentamento dos problemas da educação está no interior da própria escola: "é na escola que está o problema; é na escola que está a solução".
} 
acabam por direcionar um sentido pragmático à formação. Essa perspectiva de formação, especialmente por secundarizar os impactos dos fatores sociais, econômicos e políticos na prática docente, centraliza a responsabilidade da qualidade da educação sobre os profissionais da escola. Ao se colocar em segundo plano a análise da conjuntura material e ideológica da sociedade vigente, reforça-se a realidade excludente que historicamente tem acompanhado os filhos dos trabalhadores.

Para a classe menos abastada, o sistema educacional brasileiro tem ampliado a oferta dos cursos técnicos profissionalizantes que formam o tecnólogo, dando ênfase muito maior à formação do "como fazer" em detrimento de uma sólida formação teórica. Ao mercado de trabalho interessa mais o técnico que atende aos interesses do mercado de trabalho sem questionar sua organização.

Para reforçar essa ideia trazemos Gentili (1996) para afirmar que a educação brasileira está atrelada à empregabilidade, capacidade flexível de adaptação individual às demandas do mercado de trabalho, e que a função social da educação se esgota neste ponto; por isso, a educação deve apenas oferecer essa ferramenta necessária, o saber prático para competir nesse mercado. Nesse sentido o autor compara os currículos escolares com fast food, pois, McDonaltizar a escola supõe pensá-la como uma instituição flexível que deve reagir aos estímulos ou aos sinais emitidos por um mercado educacional altamente competitivo.

Nessa oferta de formação para o "fazer", notamos que o darwinismo social ${ }^{2}$ intensifica o processo de fragmentação do conhecimento e da divisão estrutural produzida no interior das sociedades neoliberais. Pimenta (2005), em um artigo sobre "Formação de professores: identidade e saberes da docência", alertava sobre a desvalorização do professor da educação básica ao ser concebido como simples reprodutor do conhecimento ou monitor de programas pré-elaborados. Esse professor comumente sabe resolver os problemas da sala de aula, com saberes experienciais, sem, contudo, ter posse do conhecimento teórico que deveria iluminar a sua prática. A orientação da pesquisadora para a formação do profissional docente é que teoria e prática caminhem sempre juntas e que os/as docentes da educação básica, em parceria com os/as docentes da educação superior, sejam também pesquisadores/as, construindo conhecimentos científicos a partir de sua prática, ou seja, a partir da experiência vivenciada no cotidiano da sala de aula. Essa seria a solução para superar a formação baseada na dicotomia entre teoria e prática, uma vez que ambas são muito importantes.

\footnotetext{
${ }^{2}$ Darwinismo social intensifica o processo de fragmentação e de divisão estrutural, colaborando com a manutenção do status quo e produzido no interior das sociedades neoliberais. Nesse paradigma há uma seleção natural e sempre os "mais aptos" são os que vencem..
} 
Por conseguinte, entendemos que a formação para a prática, a autoformação, o aprender pela experiência vivida, o aprender no cotidiano e o aprender a aprender ${ }^{3}$ são reforçados por essa vertente ideológica. Com a análise particularizada, e sem a correlação todo/parte e parte/todo, a prática é compreendida de modo imediato e individualizado e a sólida formação teórica (conhecimento científico) é negligenciada. Refletir por si mesmo é um processo individual, não obstante que a formação do ser humano se dê pela mediação dos instrumentos e signos, que requer o coletivo. Segundo Vygotsky (2003) ainda que a formação demande um processo intrapsíquico, este só é possível pela internalização do interpsíquico, que se desenvolve no contexto das relações que são históricas e culturais. Acrescenta o autor que esse desenvolvimento "não se dá em círculo, mas em espiral, passando por um mesmo ponto a cada nova revolução, enquanto avança para um nível superior. Chamamos de internalização a reconstrução interna de uma operação externa" (VYGOTSKY, 2003, p.74).

Poder-se-ia inferir que a formação na racionalidade prática (neotécnica) prende o professor em seus próprios conceitos cotidianos por serem marcados por um processo de formação prático-utilitária, visto que o foco de questionamento é a própria experiência e a vida dos professores, a qual deve ser refletida por ele, a fim de promover sua autoformação e encontrar soluções aos problemas vividos no cotidiano. Desconsidera-se que a atuação docente demanda a formação de conceitos científicos, os quais não se constroem na imediaticidade do mundo prático-utilitário. Segundo Martins (2007), a formação reduzida à prática cotidiana é vazia de conteúdo e limita progressivamente a compreensão e a possibilidade de intervenção crítica na realidade. Para o autor há

[...] uma forte emergência de estratégias de personalização e individualização educacionais que sugerem a formação do professor centrada na atividade cotidiana da sala de aula, na sua maneira de ser professor, centrada, portanto, em sua experiência. O saber da experiência adquire grande importância, ocupando um espaço outrora concedido à formação teórica, metodológica e técnica (MARTINS, 2007, p. 12).

Esse movimento acaba por formar um círculo vicioso de alienação, no qual a formação da consciência dos estudantes, papel essencial da educação formal, fica comprometida, pois o trabalho do professor interfere na qualidade do ato educativo, uma vez que o seu produto é diferente do de outros trabalhadores nos quais a alienação não compromete o produto do seu trabalho. O trabalho do professor não se materializa em um objeto físico, mas, sim, na humanização.

\footnotetext{
${ }^{3}$ O Relatório de Jacques Delors abarcava a necessidade de uma educação como uma ação para toda a vida onde se propunha uma educação direcionada para: aprender a conhecer, aprender a fazer, aprender a viver com os outros, aprender a ser, eleitos como os quatro pilares fundamentais da educação, preocupando com a formação do professor para o século XXI. São conceitos de fundamento da educação baseados no Relatório para a UNESCO da Comissão Internacional Sobre Educação para o Século XXI, consonantes com o ideário neoliberal.
} 
O homem demanda do processo de humanização. Como destaca Duarte (1993), ainda que o desenvolvimento do gênero humano (categoria histórica) esteja relacionado ao da espécie humana (categoria biológica), há a distinção entre ambos, pois a herança genética transmite as características da espécie humana, uma vez que essas características estão materializadas no organismo, como em qualquer espécie animal. Já as características do gênero humano não se acumulam no organismo e são apropriadas e objetivadas no interior das relações sociais concretas e históricas.

Assim, é em socialidade que se dá a existência do ser genérico (pertencente ao gênero humano); entretanto, nem sempre a apropriação de uma socialidade concreta pelo indivíduo permite "a objetivação plena desse homem enquanto ser genérico" (DUARTE, 1993, p.111), pois as formas históricas marcadas pela exploração do homem pelo homem na sociedade de classe cerceiam o desenvolvimento da genericidade do indivíduo. Assim, essa experiência do indivíduo se efetiva ao nível da genericidade em-si, na cotidianidade, e, alienada da visão essencial do real, permanece no "aparente". A ascensão à genericidade consciente em nossa sociedade (capitalista) envolve o papel central da educação emancipadora.

\begin{abstract}
A prática pedagógica tem um papel fundamental na formação do indivíduo, qual seja, o de ser mediadora entra a vivência em-si, espontânea, da genericidade e a condução consciente da vida pela relação também consciente com o processo histórico de objetivação universal e livre do gênero humano. Em outras palavras, concebo a prática pedagógica como uma prática direcionada para a elevação da consciência do indivíduo ao nível da genericidade para-si, ou seja, para a formação, pelo indivíduo, de uma relação consciente entre sua vida concreta, histórica e socialmente determinada, e as possibilidades de sua objetivação ao nível da universalidade do gênero humano (DUARTE, 1993, p.103).
\end{abstract}

A formação da genericidade para-si demanda, portanto, de consistente instrumentalização para formar o olhar crítico necessário à prática consciente do homem. Contudo, segundo Leontiev (1987, p.117), a consciência não é algo imutável ou um “espaço psíquico" homogêneo e sem qualidade, limitado pelo seu único volume e pela claridade apenas da sua iluminação, mas, sim, caracterizada por inter-relações determinadas e historicamente formadas. 
A consciência é um atributo do cérebro humano. É a unidade dos processos psíquicos que participam ativamente nas relações do sujeito com o mundo exterior e com seu próprio eu, é o grau superior do desenvolvimento da psique humana que surge no processo do trabalho e da comunicação. Assim, ela integra aspectos cognitivos, emotivos e volitivos, e a ela se integra a imaginação criadora (ou criativa) e produtiva que elabora a transformação tanto da realidade quanto do sujeito nas condições sociais. A consciência permite planejar as intencionalidades da atividade e corrigi-la em cada momento, conforme os objetivos que persegue e o produto ideal a que se propõe. No processo, a correção passa a ser reflexiva e crítica (NÚNEZ, 2009, p.6566).

Na visão marxiana é conferida à consciência de classe o seu desenvolvimento no próprio processo histórico de luta, sem que este exclua o trabalho dos teóricos da classe operária, os quais, entretanto, elaboram cientificamente a teoria com base no movimento real de luta que expressam, ou seja, a teoria se constrói em relação ao movimento político proletário e contribui com a sua sustentação. Nesse movimento há coincidência entre a luta do coletivo e a luta do indivíduo, já que todos estão envolvidos com os propósitos da classe proletária.

$\mathrm{Na}$ mesma direção, para Leontiev (1987), no desenvolvimento da consciência, coincidem a significação social e os sentidos pessoal, que são, respectivamente, "a forma sob a qual um homem assimila a experiência humana generalizada e refletida" (Ibid., p.101), e o sentido, leitura pessoal do social, elaborado na história e cultura da qual o indivíduo faz parte, sendo reelaborado pela própria história do indivíduo, "razão por que num estudo histórico da consciência o sentido é antes de mais nada uma relação que se cria na vida, na atividade do sujeito" (Ibid., p.103). Ambos (significado e sentido) estão relacionados na atividade humana, conceito fundamental para o autor que afirma ser a atividade o modo especificamente humano (indivíduo) de se relacionar com o mundo, uma vez que é por ela que o homem transforma de forma criativa o mundo e, ao mesmo tempo, ele mesmo é transformado.

Entretanto, Leontiev (1987) considera que a relação sentido e significado nem sempre assume uma estrutura integrada ${ }^{4}$, como na sociedade capitalista, na qual estes componentes apresentam-se, muitas vezes, de modo desintegrado. As assertivas do autor nos remetem ao momento vivido pelos professores na realidade engendrada pela intensificação das formas de exploração humana. O capital "sedento" não cessa as formas de sua perpetuação e, no bojo da estrutura capitalista, os homens se veem cada vez mais obrigados "a satisfazer as suas necessidades mais vitais", a vender a sua força de trabalho, a alienar o seu trabalho, "sendo o

\footnotetext{
${ }^{4}$ Ao tratar sobre o desenvolvimento histórico da consciência Leontiv (1987, p.121) aponta que na comunidade primitiva a estrutura interna elementar da consciência era caracterizada pela coincidência entre o sentido do fenômeno real para homem e as significações elaboradas socialmente, sendo a forma sob a qual os fenômenos chegavam à consciência. Marcada pela propriedade coletiva os homens viviam a relação idêntica no que se refere aos meios e frutos da produção, por isso, refletidos também de maneira idêntica na consciência individual e na consciência coletiva: "o produto do trabalho coletivo tinha o sentido de 'bem' comum". Essa formação da consciência é denominada pelo autor de 'primitiva integrada'.
} 
trabalho o conteúdo mais essencial da vida, devem alienar o conteúdo da sua própria vida" (LEONTIEV, 1987, p.129). Nessa relação com o trabalho alienado o

[...] homem tem como consequência a discordância entre o resultado objetivo da atividade humana e o seu motivo [o que impulsiona o indivíduo]. Dito por outras palavras, o conteúdo objetivo da atividade não concorda agora com o seu conteúdo objetivo, isto é, com aquilo que ela é para o próprio homem. (LEONTIEV, 1987, p.130, destaque nosso).

Nessa conjuntura, pode-se observar a separação entre o significado social e o sentido pessoal. Não raro essa é a realidade que marca os professores, na qual há uma distância entre o motivo que conduz o indivíduo e o conteúdo da sua ação. Na relação alienada o professor também procura satisfazer as suas necessidades humanas pela sua atividade, mas o seu trabalho não tem o sentido de humanizar (função social da educação formal) mas, sim, de ganhar o seu salário para, assim, atender às suas demandas.

O significado social da educação (humanização), na sociedade capitalista, não raro é corrompido e alienado diante dos interesses da classe dominante. Assim, a educação vive as contradições desse sistema no qual ao mesmo tempo a educação é envolvida tanto em mecanismos de reprodução quanto nas possibilidades de transformação da sociedade, sendo que a Formação de Professores deve garantir a compreensão desse movimento. É necessário ter claro qual é o significado social que envolve a nossa concepção de Formação de Professores.

Portanto, ao afirmar esta relação entre sentido pessoal e significado social no desenvolvimento da consciência, Leontiev (1987) parece se apoiar na ideia do proletariado "puro", na qual tanto confiava Marx, e não em uma classe marcada pela forte influência reformista à ideologia burguesa. Por exemplo temos a própria história dos membros do Partido Socialista Italiano que se renderam à reforma no lugar da tomada ao poder no início do século passado na Itália e, assim, acabaram perdendo as rédeas para o próprio Fascismo. Neste sentido, avaliamos que esta coincidência (sentido pessoal e significado social) necessária ao desenvolvimento da consciência crítica, só é possível quando firmada no coletivo marcado pelo parâmetro da igualdade e do bem comum.

Ainda amparados nos apontamentos de Leontiev (1987), consideramos que a proposta formativa materializada na realidade brasileira tem reforçado a centralidade da divisão no campo educacional entre a atividade intelectual e a atividade prática porque cada vez mais o professor tem sido chamado a atuar como mero executor e não como aquele que transforma crítica e criativamente a educação por meio da sua atividade.

As reflexões acima nos levam a ponderar que a Formação de Professores não pode ocorrer na esfera cotidiana, como sugerem os que valorizam o "aprender fazendo", mas na 
sólida formação que possibilite a práxis criadora. A Formação de Professores na perspectiva marxiana requer o desenvolvimento do conceito científico para a apropriação e a objetivação da genericidade para-si, com o intento da formação da individualidade para-si (humanização).

Na vertente neotecnicista, portanto, a formação é pensada na esfera da genericidade emsi, pois o professor é motivado a refletir no e sobre o cotidiano, cujo objeto é a própria prática. Segundo Kosik (2010) as pessoas vivem a cotidianidade como em uma atmosfera natural, sem questionar essa cotidianidade. Assim, o professor ao refletir de forma circunscrita a vida cotidiana da escola, fica restrito ao âmbito fenomênico, pois na cotidianidade

O modo de viver se transforma em um instintivo, subconsciente, irrefletido mecanismo de ação e de vida. As coisas, os homens, os movimentos, as ações, os objetos circundantes, o mundo, não são intuídos em sua originalidade e autenticidade, não se examinam nem se manifestam: simplesmente são; e como um inventário, como parte de um mundo conhecido são aceitos. [...] Nesta o indivíduo cria para si relações, baseada na própria experiência, nas próprias possibilidades, na própria atividade e daí considerar esta realidade como o seu próprio mundo (KOSIK, 2010, p.80, destaques do autor).

O mundo fenomênico é compreendido como o próprio mundo, pois o indivíduo/professor não tem elemento para ver além da aparência. Deste modo, ao limitar a Formação de Professores ao campo da individualidade e da prática cotidiana, lança-se sobre eles uma tarefa para além das suas possibilidades. Sem o aporte do conhecimento científico, ele está fadado à mera reprodução alienada de receituários de práticas pedagógicas já presentes na escola, como: receitas orientadas por especialistas; manuais didáticos; matrizes de referência; ou, ainda, os conteúdos em forma de questões cobradas nas avaliações externas.

Essa concepção acaba por delegar ao professor a responsabilidade pelo seu próprio desenvolvimento profissional. Avaliamos que a reação limitada dos professores diante do formato de avaliação externa que os responsabilizam pelo sucesso ou fracasso do processo educacional, está em consonância com essa postura de formação. Ao não preparar o professor para a análise da totalidade, das contradições e múltiplas determinações que estão em relação na constituição da realidade, acaba levando-o à aceitação da responsabilidade atribuída a ele. Mesmo que o professor recuse tal posição (de culpado), não tem elementos sólidos que o autorizem de forma crítica a reagir/resistir.

Por conseguinte, essa concepção de formação empobrecida da análise crítica conjuntural, com uma visão pontual e simplista da realidade, forma, como salienta Frigotto (1999), um professor que age como um "cachorro que corre em círculo". Contrapondo-se a tal visão, o que propomos no presente artigo é a concepção na qual o foco não está na prática pela prática, mas na visão do professor como sujeito histórico que deve compreender as contradições 
da realidade, em especial, da educação, o que demanda uma formação que potencialize esse professor à síntese datada e histórica. Tal concepção requer um processo de formação pautado em uma epistemologia da práxis que pensa a formação da consciência para a transformação.

\title{
Epistemologia marxiana e a práxis revolucionária: substrato da formação docente
}

A problematização da Formação de Professores nos leva à reflexão de como entendemos ser possível desenvolver/construir o conhecimento necessário à genericidade para-si. Tal questão aponta para a demanda de delinearmos nossa concepção epistemológica. Admitimos, primeiramente, que é possível conhecer a "coisa em si” e que a dialética permite-nos conhecêla. Mas salientamos que

\begin{abstract}
A dialética não atinge o pensamento de fora para dentro, nem de imediato, nem tampouco constitui uma de suas qualidades; o conhecimento é que é a própria dialética em uma das suas formas; o conhecimento é a decomposição do todo. O "conceito" e a "abstração", em uma concepção dialética, têm o significado de método que decompõe o todo para poder reproduzir espiritualmente a estrutura da coisa, e, portanto, compreender a coisa (KOSIK, 2010, p.18).
\end{abstract}

Nessa vertente, considera-se que a realidade não se apresenta imediatamente ao homem; por isso, na dialética marxista, se distingue a representação e o conceito da coisa em si, que são duas dimensões de conhecimento da realidade, ou mais, duas qualidades da práxis humana. Tal fato decorre porque o homem perante a realidade não se constitui como um abstrato sujeito cognoscente e, sim, como ser que age objetiva e praticamente sobre a natureza diante de suas necessidades, permeado por um conjunto de relações sociais. Nesse sentido, o homem inserido concretamente neste mundo experimenta, inicialmente, uma ação prático-utilitária por meio da qual ele cria as suas próprias representações das coisas, gerando as formas fenomênicas da realidade. Entretanto, essas formas fenomênicas são distintas e mesmo contrárias em relação ao núcleo interno essencial e seu conceito correspondente da coisa.

A prática utilitária é, portanto, envolvida pelo senso comum e não pela compreensão consciente do real. Na formação docente não podemos nos deter apenas na prática que paira entre os professores das escolas. É necessário avançarmos para além da pseudoconcreticidade, desnaturalizar o que se coloca como natural.

O complexo dos fenômenos que povoam o ambiente cotidiano e a atmosfera comum da vida humana, que, com a sua regularidade, imediatismo e evidência, penetram na consciência dos indivíduos agentes, assumindo um aspecto independente e natural, constitui o mundo da pseudoconcreticidade (KOSIK, 2010, p. 15). 
Como é característico, nesse mundo da pseudoconcreticidade permanecemos na superficialidade, ficamos distantes do que é realmente essencial, vivemos uma práxis fetichizada. Por conseguinte, na formação docente é importante perceber que a essência não se apresenta imediatamente, ela é mediata ao fenômeno que ao mesmo tempo a revela e a esconde. Para o professor para captar a essência é necessário analisar o fenômeno, entender como a coisa em si se manifesta nele. Pela manifestação do fenômeno o professor pode apreender a essência, mas ambos (fenômeno e essência) não constituem a mesma coisa. Entretanto, na pseudoconcreticidade o fenômeno e a essência são tomados como iguais, quando de fato o fenômeno se manifesta imediatamente e a essência, a estrutura da realidade, não se manifesta de forma direta, demandando uma análise crítica sustentada pelo pensamento científico. Cabe ao processo formal/intencional de formação do professor, seja em nível da formação inicial ou continuada, possibilitar tal preparação.

O processo de formação do conceito científico tem como base o pensamento cotidiano que o professor já formou ao longo da sua vida. Na concepção marxiana de formação docente compreende-se, com as leis da dialética, o movimento entre ambos (conceito científico e cotidiano) pois, ao mesmo tempo em que estes "se desenvolvem em direções opostas, os dois processos estão intimamente relacionados" (VYGOTSKY, 2005, p.135).

Ao forçar a sua lenta trajetória para cima, um conceito cotidiano abre o caminho para
um conceito cientifico e o seu desenvolvimento descendente. Cria uma série de
estruturas necessárias para a evolução dos aspectos mais primitivos e elementares de
um conceito, que dão corpo e vitalidade. Os conceitos científicos, por sua vez,
fornecem estruturas para o desenvolvimento ascendente dos conceitos espontâneos da
criança em relação à consciência e ao uso deliberado. Os conceitos científicos
desenvolvem-se para baixo por meio dos conceitos espontâneos; os conceitos
espontâneos desenvolvem-se para cima por meio dos conceitos científicos
(VYGOTSKY, 2005, p.136).

Dentre os pressupostos centrais desse processo, é necessário considerar a categoria contradição que possibilita o movimento. Em meio às leis da dialética, temos a lei da unidade e da luta dos contrários, que compreende que uma dada realidade apresenta, ao mesmo tempo, o seu contrário, e que ambos estão em permanente tensão, viabilizando o movimento e a suscetível transformação. Todavia a transformação não significa descartar o velho, pois, como lei da dialética, temos também a negação da negação, na qual a superação implica negar e, ao mesmo tempo, manter elementos do velho. Portanto, não podemos negar o conhecimento com o qual nos deparamos no cotidiano dos professores e que são construídos por eles, mas não podemos ficar limitados a eles e, sim, tomá-los como base para a construção de conhecimento entremeados na construção teórica. 
As premissas de que partimos não são bases arbitrárias, dogmas; são bases reais que só podemos abstrair na imaginação. São os indivíduos reais, sua ação e suas condições materiais de existência, tanto as que eles já encontraram prontas, como aquelas engendradas de sua própria ação (MARX; ENGELS, 2008, p.10).

Esse movimento ocorre de modo dialético pois é na luta com o conceito cotidiano, do qual o professor já dispõe diante da materialidade vivida, que a formação do conceito científico é construída, mas isso não significa o descarte do velho conhecimento porque o novo leva consigo elementos do velho. E esse desenvolvimento se dá na luta dos contrários (conhecimento cotidiano e científico) que formam a totalidade concreta. Deste modo, a formação envolve uma transformação qualitativa dos conceitos dos docentes.

\begin{abstract}
A totalidade concreta como concepção dialético-materialista do conhecimento do real (cuja dependência face à problemática ontológica da realidade já ressaltamos repetidas vezes) significa, portanto, um processo indivisível, cujos momentos são: a destruição da pseudoconcreticidade, isto é, da fetichista e aparente objetividade do fenômeno, e o conhecimento de sua autêntica objetividade; em segundo lugar, conhecimento do caráter histórico do fenômeno, no qual se manifesta de modo característico a dialética individual e do humano em geral; e, enfim, o conhecimento do conteúdo objetivo e do significado do fenômeno, da sua função objetiva e do lugar histórico que ela ocupa no seio do corpo social (KOSIK, 2010, p.61).
\end{abstract}

O conceito científico caminha, assim, do abstrato ao concreto, mas a abstração com base na essência do objeto e não em seus aspectos fenomênicos. Esse conceito envolve compreender os atributos essenciais do objeto da docência, assim como a projeção do conceito aos demais objetos da realidade a ele relacionados. É, portanto, na atividade orientada, organizada e sistemática que o conceito científico se desenvolve. Esse processo complexo promove um

[...] sistema de relação de conceitos, no trânsito do geral para o particular e vice-versa, dependendo de cada nível de desenvolvimento dos significados e da estrutura de generalização predominante em determinado nível. Nos conceitos científicos, o geral predomina sobre o particular, em um sistema epistêmico (NUNEZ, 2009, p.43).

Assim, um desafio a enfrentarmos na Formação de Professores na vertente materialista é não negar, ou desconsiderar, a contradição e os conflitos presentes no conhecimento sobre a docência mas, sim, tomá-la como intrínseca das nossas análises e construirmos, a partir desta, as nossas sínteses (históricas/provisórias). Todavia, não existe apenas uma contradição ou o mesmo modo de contradição, mas sim, contradições, as quais estão entrelaçadas, mas, como aponta Marx (1982), é possível extrairmos dessas múltiplas contradições sínteses historicamente datadas e que abrem possibilidades para novas contradições (com nova natureza).

Portanto, na formação docente o processo de desenvolvimento do conceito científico ocorre do abstrato ao concreto e, instrumentalizado pela formação, o professor promove as suas 
objetivações. Por fim, na segunda tese sobre Feuerbach Marx (2008, p.100), destaca-se que atribuir ao pensamento humano uma verdade objetiva não é uma questão teórica, mas, sim, prática, pois "é na práxis que o homem precisa provar a verdade, isto é, a realidade e a força, a terrenalidade do seu pensamento" e a discussão sobre a realidade do pensamento isolada da práxis, segundo o autor, é puramente escolástica. Nesse sentido, é necessário que a formação docente instrumentalize o professor para objetivar na realidade docente uma práxis revolucionária.

\section{A favor de uma epistemologia da práxis: considerações finais}

Os homens ao produzirem (na e em atividade) os meios para a sua existência, produzem a própria vida material. Nesse contexto se constitui uma consciência comum do homem e, segundo Vázquez (1977, p.8), “sem transcender os limites da consciência comum, não só é impossível uma consciência filosófica da práxis, como também uma práxis que se eleve a um nível superior - isto é, criador - a práxis espontânea ou reiterativa do dia a dia”. De acordo com esse autor, para chegarmos a uma verdadeira concepção filosófica da práxis, é necessário apresentá-la intimamente vinculada ao conceito de criação, ou seja, na capacidade humana de “instaurar uma nova realidade que não existe por si mesma”, mas, não contrário, é construída, é histórica (VÁZQUEZ, 1977, p.47). Nossa concepção, portanto, segue na contramão dos racionalistas práticos que concebem a Formação de Professores limitada ao mundo da consciência comum, sem garantir o desenvolvimento do pensamento científico sobre a docência, o qual a subsidie à apropriação e objetivação de uma práxis criadora.

Seguir essa vertente envolve a admissão de que a realidade não se apresenta imediatamente ao homem, demanda da ciência a fim de alcançar os seus fundamentos (MARX, 1982). Portanto, na docência é necessário que o professor tenha base para a separação entre o fenômeno e a essência, entre o que é secundário e o que é essencial. Essa separação é o que diferencia a ciência da prática-utilitária, a qual toma o mundo da aparência como mundo real. No conhecimento científico há a demanda da decomposição do todo, a fim de apontar o que é específico da realidade. Ainda que o conhecimento sobre a docência tome como base a pensamento já desenvolvido sobre a realidade, não podemos ficar restritos a ele.

A destruição da pseudoconcreticidade como método dialético-crítico, graças à qual o pensamento dissolve as criações fetichizadas do mundo reificado e ideal, como método revolucionário de transformação da realidade. Para que o mundo possa ser explicado "criticamente", cumpre que a explicação mesma se coloque no terreno da "práxis” revolucionária. (KOSIK, 2010, p.22, destaque do autor). 
Para se constituir em práxis revolucionária cabe o compromisso na formação de professores Formação de Professores em colocar a prática como fundamento do conhecimento e o conhecimento como fundamento da prática. Nesse prisma é preciso coerência na formação docente, assumindo como princípio formar o método não só pelo conteúdo, mas pelo próprio método de formação, ou seja, a própria forma como desenvolvemos o conteúdo da formação é conteúdo formativo pois, "conhecer é conhecer objetos que se integram na relação entre o homem e o mundo, ou entre o homem e a natureza, relação que se estabelece graças à atividade prática humana" (VÁZQUEZ, 1977, p.153), assim como a produção de uma teoria envolve a função da transformação do mundo. Contudo, como a teoria em si não transforma a realidade, esta deve sair de si mesma, deve ser objetivada. Entre a teoria e a atividade transformadora se insere um trabalho de

[...] educação das consciências, de organização dos meios materiais e planos concretos de ação; tudo isso como passagem indispensável para desenvolver ações reais, efetivas. Nesse sentido, uma teoria é prática na medida em que materializa, através de uma série de mediações, o que antes só existia idealmente, como conhecimento da realidade ou antecipação ideal de sua transformação (VÁZQUEZ, 1977, p.207).

Vale ressaltar ainda que a totalidade se apresenta também como categoria central na dialética materialista porque esta constitui a busca pelo apreender da realidade em suas íntimas leis, apontando as conexões internas. Entretanto, no exame da totalidade, não podemos nos limitar à análise do todo e das partes, mas garantir seu caráter dialético, assumindo a unidade das contradições e a dialética da lei e da casualidade, da essência e dos aspectos fenomênicos, pois são, justamente, os elementos contrários que formam a totalidade (em permanente devir). Esse processo é central se pretendemos a 'destruição' da pseudoconcreticidade como conteúdo da Formação de Professores

A compreensão dialética da totalidade significa não só que as partes se encontram em relação de interna interação e conexão entre si e com o todo, mas também que o todo não pode ser petrificado na abstração situada por cima das partes, visto que o todo se cria a si mesmo na interação das partes (KOSIK, 2010, p. 50, destaque do autor).

$\mathrm{Na}$ análise de Kosik (2010) a perspectiva materialista de "totalidade concreta" não reside na tentativa de esgotar todos os fatos da realidade, no lugar disso "[...] totalidade significa: realidade como um todo estruturado, dialético, no qual ou do qual um fato qualquer (classe de fatos, conjunto de fatos) pode vir a ser racionalmente compreendido" (Idem, p.44).

Considerar essas questões na formação docente indica a necessidade de não matarmos a própria dialética presente na realidade educacional; por isso, a partir da epistemologia explicitada é preciso, na formação, buscar entender o trabalho docente, sem negar a totalidade 
histórico-social que os sustentam, a condição material vivida por eles e as contradições da realidade que engendram determinações, mas, também, as possibilidades da transformação. A realidade da escola não se apresenta imediatamente ao professor, demanda de análise sistemática, buscando os movimentos que a compõem a fim de compreender o que está obscuro e confuso, para chegar ao conceito do todo agora abarcando as suas determinações e relações (sustentada pela formação do conhecimento científico).

Filiados à epistemologia marxiana na formação docente, para sermos coerentes, vemos ser necessária a objetivação da formação de sujeitos que se percebem como históricos e promovem uma práxis revolucionária. Nesse contexto, o trabalho é compreendido como atividade vital do ser humano, como ação criativa e transformadora. Os professores assim formados não assumem uma postura passiva diante das políticas públicas de educação, estão instrumentalizados para a resistência e, assim, analisam e apontam a totalidade (múltiplas determinações) que interfere nos resultados do seu trabalho.

Necessitamos, portanto, da formação que, contrariando os interesses do capital, seja vigorosa em teorias e práticas, pautada no coletivo na construção de um mundo justo, onde todos tenham as mesmas condições reais de vida. Para atingir tal fim, é importante que na Formação de Professores haja avanços da epistemologia da prática para a epistemologia da práxis criadora.

\section{Referências}

DALBERIO, M.C.B; DALBERIO, O. Aspectos metodológicos e filosóficos que orientam as pesquisas em educação Revista Iberoamericana de Educación. n. ${ }^{\circ} 43 / 5$ - 25 de julio de 2007. Disponível em: https://rieoei.org/historico/deloslectores/1645Borges.pdf Acesso em 20 jan. 2018.

BRASIL. Ministério da Educação e do Desporto. Planejamento político-estratégico: 1995 1998. Brasília, DF, 1995.

DUARTE, Newton. O Gênero humano. In. DUARTE, Newton. A individualidade para-si: contribuição a uma Teoria Histórico-Social da Formação do Indivíduo. Campinas: Autores Associados, 1993.

FRIGOTTO, Gaudêncio. A formação e a profissionalização do educador: novos desafios. In: GENTILI, Tomaz Tadeu da Silva (org.). Escolas: quem ganha e quem perde no mercado educacional do neoliberalismo. Brasília: BNTE, 1999.

GENTILLI. P.(org). Neoliberalismo e educação: manual do usuário. In SILVA, Tomaz Tadeu da \& GENTILLI, Pablo. (orgs.) escola S.A. Quem ganha e quem perde no mercado educacional do neoliberalismo. CNTE. 1996. 
KOSIK, Karel. Dialética do concreto. Trad. NEVES, Célia; TORÍBIO, Alderico. Rio de Janeiro: Paz e Terra, 2010.

LEONTIEV, Aleksei N. Sobre o desenvolvimento da história da consciência. In. LEONTIEV, Aleksei N. O desenvolvimento do psiquismo. Lisboa: Horizonte Universitário, 1987.

MARTINS, Lígia Márcia. A formação social da personalidade do professor: um enfoque vigoskiano. Campinas, SP: Autores Associados, 2007.

MARX, Karl; ENGELS, Friedrich. A Ideologia Alemã. Trad. COSTA, Luis Claudio de Cartro e. São Paulo: Martins Fontes, 2008.

MARX, Karl. O Capital. Livro I. Rio de Janeiro: Editora Guanabara, 1982.

NÚÑEZ, Isauro Beltrán. A formação de conceitos científicos na escola e a Teoria da Atividade de A. N. Leontiev. In. NÚÑEZ, Isauro Beltrán. Vygotsky, Leontiev, Galperin: formação de conceitos e princípios didáticos. Brasília: Liber Livro, 2009.

PIMENTA, S. G. (Org.) Formação de professores: identidade e saberes da docência: In: PIMENTA, S. G. (Org.).Saberes Pedagógicos e atividade docente. 4 ed. São Paulo: Cortez, 2005. (Saberes da docência).

RICHTER, Leonice Matilde. Trabalho docente, políticas de avaliação em larga escala e accountability no Brasil e em Portugal. 2015. Tese (Doutorado) - Programa de Pósgraduação em Educação, Universidade Federal de Uberlândia, Uberlândia, 2015.

SCHÖN, Donald. Formar professores como profissionais reflexivos. In: NÓVOA, A. (Org.). Os professores e a sua formação. 3. ed. Lisboa: Dom Quixote, 1997.

SCHÖN, Donald. Educando o profissional reflexivo: um novo design para o ensino e a aprendizagem. Porto Alegre: Artes Médicas, 2000.

TARDIF, Maurice. Saberes docentes e formação profissional. Petrópolis: vozes, 2002.

VÁZQUEZ, Adolfo Sánchez. Filosofia da Práxis. Trad. CARDOSO, Luiz Fernando. Rio de Janeiro: Paz e Terra, 1977.

VYGOTSKY, LevSemenovich. Pensamento e Linguagem. Tad. CAMARGO, Jefferson Luiz. São Paulo: Martins Fontes, 2005.

VYGOTSKY, Lev Semenovich. A formação social da mente - o desenvolvimento dos processos psicológicos superiores. Trad. NETO, José Cipolla; BARRETO, Luiz Silveira Menna; AFECHE, Solange Castro. São Paulo: Martins Fontes, 2003. 